\section{New space agency proposed by West German parliament \\ Munich}

WEST Germany will coordinate its space programme through a new private agency, if the proposal of Research and Technology Minister Heinz Riesenhuber is accepted by the German Bundestag (parliament). The proposal, likely to be approved by the Bundestag in September, was introduced on 24 June.

In an unrelated move, the Bundestag's budget committee agreed to double the 1987 West German space budget to DM 502 million. The money is divided among three quite costly European Space Agency (ESA) projects - the booster rocket Ariane, the space shuttle Hermes and the manned space station Columbus, which is to be built by the United States with ESA cooperation. The total cost to West Germany for the three is now estimated at about DM 8,000 million.

Until now, the West German space programme has been administered by the German Aerospace Research Establishment (DFVLR), which in turn reports to the Research and Technology Ministry (BMFT). This led to an uncomfortable situation, as the DFVLR was politically responsible for assigning contracts as well as for carrying them out.

The proposed agency, the German Agency for Space Flight (DARA), would negotiate with ESA and other space authorities on West Germany's behalf and coordinate industry and scientists as well as ministries that have an interest in the

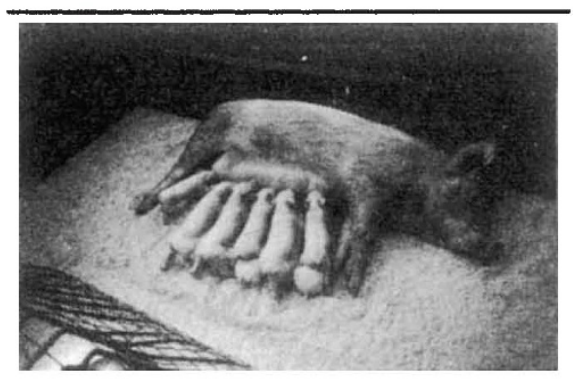

\section{Transgenic sow \\ London}

A TRANSGENIC SOW and her litter, produced as part of a collaborative research programmme between Animal Biotechnology Cambridge Ltd $(A B C)$ and Embryogen Inc., of Ohio. $A B C$ is a recently formed company that has taken over the former government-funded Animal Research Station at Cambridge, England. Among ABC's first venture partners is a consortium of city investors, including Biotechnology Investments Ltd, which has committed more than 11 million to the new company. Under the scientific directorship of Dr Christopher Polge, ABC's first commercial project is a three-year programme to develop techniques for large-scale production and freezing of cattle embryos suitable for transplant. Other areas of research include transgenesis and sex pre-determination.

Simon Hadlington space programme. Its budget would probably be several tens of millions of deutschemarks. The DFVIR would give up its political role and simply carry out the contracts awarded it by the agency.

DARA, if indeed approved, will be a private agency, which is not bound by West German law to pay salaries on the public service wage scale as are government institutions. The BMFT hopes that the higher pay will attract better people to the agency.

Not surprisingly, the DFVLR is not happy with the Riesenhuber plan, which would relieve it of up to 100 employees in the coming years and reduce its scope by about 20 per cent. The chairman of the DFVLR, Walter Kröll, has submitted a reorganization plan of his own under which political and scientific functions of the space programme would also be divided.

The biggest advantage of the Kröll plan, said DFVLR official Rüdiger Clausen, is that it does not require a larger investment. Founding an entirely new agency, especially if it is far from the Cologne headquarters of the DFVLR, will be very costly. The location of DARA has already become a hot political topic in various Länder.

But the most logical place to put the new agency would be in Cologne, possibly in the same building as the DFVLR, hinted Bundestag member Catenhusen. This plan would foil the apparent designs of Bavarian Minister-President FranzJosef Strauss to bring the entire German space programme to Bavaria. Earlier this year, Munich (Bavaria's capital) tried to outbid Cologne for the right to expand its DFVLR facilities. The attempt failed, as Cologne raised its contribution as well. The facilities remain split between the two cities.

Even though a positive verdict is expected for DARA, the larger question of German participation in the Ariane, Hermes and Columbus projects is still wide open. Catenhusen and others vocally oppose continued participation, at least in Hermes and Columbus, as the stakes inevitably go up.

\title{
Education reform is priority of the British government
}

London

THE British government last week unveiled its programme for the parliamentary session to November next year which, among other things, will substantially change the education system and patent law. The programme, outlined by the Queen at the state opening of parliament, is one of the heaviest for some time.

The new education legislation, one of 17 bills to be processed by the government, will ensure that parents are given more choice in the style and location of their children's education and there will be a new curriculum for schools, subjecting pupils to four formal achievement tests by the age of 16 .

Despite the government's overall majority of just over 100 seats in the House of Commons, the proposed legislation is likely to provoke much hostility from those who claim that the deficiencies of the current system are the result of inadequate funding and cannot be cured by the legislation.

Certainly, studies in the past few years have highlighted the shortage of science teachers, particularly in physics; this shortfall and others in mathematics and the applied sciences/technology are due to an inability to match the salaries offered by industry to technical and numerate graduates.

The legislation is also meant to guarantee that the nation's education system is controlled more centrally through the Department of Education and Science (DES) which, under the current system, has less influence on schooling in some areas than the local education authority. In further education, the same philosophy applies, and the new Education Act will allow the 29 polytechnics and other colleges to become "free-standing corporate bodies outside local authority control". It will also ensure that the curriculum adopted by these colleges reflects national needs and that "their governing bodies would have strong representation from industry, commerce and the professions".

The Queen's speech also confirmed the belief (see Nature 327, 549; 1987) that the government would reintroduce legislation, jettisoned because of time constraints before the general election, to change copyright and patent law.

Apart from devising a modern legislative framework to protect British products from piracy, the current gaps in copyright law, dealing with computer outputs and databases, are to be plugged. The legislation will also seek to provide better protection for 'intellectual property'. "The main provisions are to encourage investment in new design by introducing or extending protection to designs; reform patent law, among other things, to increase competition in patent advice and reduce the expense of patent litigation."

Bill Johnstone 